\title{
Surgical Anatomy of the Infratemporal Fossa: Book Review
}

\author{
Edited by \\ John D Langdon, Barry KB Berkowitz, Bernard J Moxham \\ UK: Taylor \& Francis: 2003: 230 pp: 1-899066-79-9 (ISBN)
}

Reviewed by

Huseyin Avni Balcioglua

Gulseren Kokten a,b

Even it was published in 2003, it would be advisable to revisit this book, since it is a 'must have' not only for dental students, oral and maxillofacial surgeons, general dentists and anatomists but also for the head and neck surgeons.

This multi-author book is 230 pages long and is presented in 9 well-ordered chapters. One of the editors of the book (Langdon) is a maxillofacial surgeon and the other two (Berkowitz and Moxham) are anatomists.

The book benefits from being a text that was written with a clear plan in mind. The chapter on TMJ and pterygopalatine fossa is one of the best chapters in the book with respect to the cadaver and surgery photos and realistic illustrations employed. The chapter devoted to trigeminal pain is highly satisfactory for a general overview as including the anatomical and physiopathological basis. The treatment and surgical procedures for trigeminal pains are presented dealing with anatomical aspects. Facial nerve and parotid gland are also under an individual section. An interesting and contemporary topic is that of local aneasthesia, starts with a detailed neuroanatomical description of the region. The surgical approaches to the infratemporal fossa are very well explained in the chapter with the same title and create a better understanding of the complex principles and potential applications in the field. Tumours and tumour like disorders presented in a seperate chapter may be of interest to the surgeons of various disciplines.

The text is well-written and well-referenced, and all of the photographs are of a high quality and resolution. It describes in detail and in colour throughout the full range of the infratemporal fossa alongside carefully selected and appealing cadaver and surgery photos, radiographs and illustrations. To explain the general concepts in clinical anatomy, especially in the field of maxillofacial surgery, in an understandable way is quite troblesome. This book succeeds in this task. Finally, this book is of considerable interest for all involved with and dealing with the infratemporal fossa, whether as oral and maxillofacial surgeons performing in the area or as anatomists investigating the cranium.

a Department of Anatomy, Faculty of Dentistry, Istanbul University, Istanbul, Turkey.

b Head of Deparment of Anatomy, Chairwoman of Basic

Medical Sciences, Istanbul University, Istanbul, Turkey. 